\title{
A simple and rapid RP-HPLC method for the assessment of cobalamin (vitamin B12) in tilapia and snoek fishes
}

\author{
Labaran IBRAHIM ${ }^{1}$ ID, Aminu USMAN $^{2}$ (D) \\ ${ }^{1}$ Department of Biochemistry, Faculty of Science, Federal University Duste, Jigawa State, Nigeria \\ ${ }^{2}$ Department of Biochemistry, Faculty of Natural and Applied Sciences, Umaru Musa Yar'adua University, Katsina State, Nigeria
}

Received: 28.04 .2021

- $\quad$ Accepted/Published Online: 13.10 .2021

Final Version: 27.04 .2022

\begin{abstract}
This study developed a rapid reversed-phase high-performance liquid chromatography (RP-HPLC) method equipped with a $\mathrm{UV}-\mathrm{V}$ is detector. The aquaponics system $>$ s tilapia and marine snoek fishes were extracted using an autoclaving process and enzymatic treatment. The technique enabled the separation and quantification of cobalamin present in these fishes extracts. Phenomenex Luna $5 \mu \mathrm{m} \mathrm{C18} \mathrm{(2)} 100 \mathrm{~A}$ LC-column $(150 \times 4.6 \mathrm{~mm})$ was used as a stationary phase, while the mobile phase consisted of methanol and phosphoric acid in a ratio of 35:65 (v/v), respectively. The developed method was revealed to be rapid (a retention time of less than 5.0 $\mathrm{min}$ ), linear $\left(\mathrm{R}^{2}=0.9988\right)$, sensitive (limits of detection and quantification showed to be 0.0004 and $0.0011 \mu \mathrm{g} / \mathrm{mL}$, respectively), precise (percentage relative standard deviation of $0.14 \%$ to $0.76 \%$ ), and accurate (percentage mean recovery of $87.44 \pm 0.33 \%$ to $97.08 \pm 0.74 \%$ ). The quantified concentrations of this vitamin in extracts of tilapia and snoek fishes were found to be $08.95 \pm 0.35$ and $14.97 \pm 0.04 \mu \mathrm{g} /$ $\mathrm{mL}$, respectively. Therefore, we suggested that the developed RP-HPLC technique could be applicable for quality control evaluation in the food and pharmaceutical industries. Besides, the method could be vital for diagnostic analysis in clinical laboratories.
\end{abstract}

Key words: Isocratic, precise, stationary phase, chromatography, retention time, limit of detection

\section{Introduction}

Vitamins are organic chemical compounds of large categories required in minor concentrations for normal immune and catalytic functions, body growth, repair, and development [1,2]. Vitamin deficiency-related physiological disorders or abnormalities are associated with their inadequate amounts in diets [3]. Night blindness and mental retardation are examples of diseases associated with vitamins deficiency, and this depends on which specific vitamin is absent or deficient [4]. For instance, Nicotinamide (vitamin $\mathrm{B}_{3}$ ) is essential for carbohydrate metabolism and DNA repair by transfer reactions of nonredox adenosine diphosphate-ribose [4]. Pyridoxine (vitamin $\mathrm{B}_{6}$ ) plays a vital role in riboflavin activity as a coenzyme for different respiratory enzymes and transamination of amino acids [4].

Cobalamin (vitamin $\mathrm{B}_{12}$ ) is a water-soluble vitamin with cobalt as a central atom. Cyanocobalamin is another popular name for cobalamin. The name applies to any of the cobalamins with identical biological functions [5]. It existed in 4 different forms: methylcobalamin, hydroxocobalamin, cyanocobalamin, and 5'-deoxyadenosylcobalamin [6,7].

Cyanocobalamin is the nonnatural form of this vitamin used for food product fortification due to its high stability [6]. Production of cobalamin is mainly by microorganisms [6]. Nevertheless, it can be naturally present in animal-derived food substances like liver, meat, egg, and synthetic form as in dietary supplements [6,8]. However, cobalamin is not mostly readily available in materials of plant origin [6]. From the report of [9], this vitamin plays a vital role in homocysteine balance, a risk factor for arteriosclerosis. In addition, cobalamin serves as a coenzyme for many essential enzymes in onecarbon (methyl) metabolism, involved in human growth and development [10]. Moreover, it is significant for hemoglobin synthesis and for normal functioning of the brain and nervous system [5]. The daily recommendation of cobalamin is $1 \mu \mathrm{g}$. Due to its low absorption rate in the small intestine, $3 \mu \mathrm{g}$ amount may be required [10]. In normal populations, the deficiency of this vitamin is rare. Nevertheless, eating disorders, elderly individuals, vegetarians or vegans, infants, and pregnant women can be susceptible to its deficiency because of their physiological needs and prescribed dietary requirements [11]. As recommended by the American Dietary Guideline (ADG), a cobalamin dietary supplement can be adequate for individuals at risk of its deficiency as an alternate food nutrient source [12].

* Correspondence: labaranibrahim80@gmail.com 
This vitamin occurs in an accessible free form or bound to other molecules such as protein. If bound, it can be released by heating at $98^{\circ} \mathrm{C}$ for $30 \mathrm{~min}$ with potassium cyanide as reported by [13], or through autoclaving at $121^{\circ} \mathrm{C}$ using buffer solution and excess potassium cyanide [14]. Samples treatment with $\alpha$-amylase for $3 \mathrm{~h}$ at $37^{\circ} \mathrm{C}$ and incubation for 35 min at $100{ }^{\circ} \mathrm{C}$ is another possible process for its release [15].

From the report of [16], a microbiological assay using Lactobacillus leishmania could be another applicable method of this vitamin analysis. The microbial assay method usually has a low specificity in some food matrices and is timeconsuming [15,17]. Also, diverse reverse-phase high-performance liquid chromatography (RP-HPLC) methods for the evaluation of this water-soluble vitamin were reported in milk [18], meat product [6], okra [19], dietary supplement, and ingredients [16,20,21] as well as blood serum [22].

Nevertheless, there is a scarcity of data in published literature for cobalamin assessment in fishes using the isocratic RPHPLC method. Therefore, in this study, we intended to determine the level of this vitamin from the extracts of aquaponics tilapia and marine snoek fishes using the RP-HPLC method with a UV-vis detector.

\section{Materials and methods}

The purchase of all samples for our study work was on 15.01.2021. The acquired fresh aquaponics tilapia and marine snoek fishes were from Sabon Gari market situated in Fagge Local Government, Kano State, Nigeria. The transportation of each sample was in separate clean polyethylene bag to the laboratory for experimental analysis. Each sample was separately cleaned well with distilled water, dried using a blotting paper, and stored at $-20^{\circ} \mathrm{C}$ before analysis.

Various extraction processes of cobalamin were previously reported in $[15,23]$. In this study, the extraction process for the release of the cobalamin from each fish sample was carried out using acidic autoclaving and enzymatic treatment for its proper separation from other components and to obtain a maximum yield, respectively. Each fish sample was chopped out separately into pieces and homogenized using a Waring blender. To approximately $10 \mathrm{~g}$ of each homogenized fish sample, $100 \mathrm{~mL}$ of sulfuric acid solution $(0.1 \mathrm{Eq} / \mathrm{L})$ was added, autoclaved at $121{ }^{\circ} \mathrm{C}$ for 20 min. The cooling of each autoclaved sample extract was at room temperature, and the $\mathrm{pH}$ was adjusted to $5.8 \mathrm{using} 2.5 \mathrm{M}$ sodium acetate solution. Besides, $\alpha$-amylase $(70 \mathrm{mg})$ and $1 \%$ potassium cyanide $(2 \mathrm{~mL})$ were added, vortexed properly, and kept overnight at room temperature. Each extract was then filtered using a filter paper (Whatman No. 1). The dilution of each filtrate was by using a phosphate buffer, $\mathrm{pH}=5.8$ (diluting solution) in a ratio of $1: 2(\mathrm{v} / \mathrm{v})$, respectively. Finally, the filtration of each diluted fish extract was through a micropore syringe filter $(0.22 \mu \mathrm{m})$ into amber HPLC vials for chromatography. All reaction vessels were covered with aluminum foil during the extraction processes to prevent photo-induced degradation of analytes. Figure 1 illustrates the extraction processes of cobalamin from the study samples.

The preparation of a standard (cyanocobalamin) stock solution was as previously described by [24], with a modification in the preparation of working standard concentrations. The preparation of the stock solution was by dissolving $10 \mathrm{mg}$ of cyanocobalamin in $25 \mathrm{~mL}$ of a diluting solution (phosphate buffer, $\mathrm{pH}=5.8$ ). A standard working solution of $200 \mu \mathrm{g} / \mathrm{mL}$ was generated using the standard stock solution to generate $0.1 .0 .25,0.5,1,2.5,15,20,50$, and $120 \mu \mathrm{g} / \mathrm{mL}$ concentrations for further dilution using diluting solution.

The purchased external standard (cyanocobalamin) and a-amylase were from Sigma-Aldrich, St. Louis, USA. The sourced HPLC grade methanol was from Merck KGaA, Darmstadt, Germany, CAS-No. 67-56-1. The acquired orthophosphoric acid and sulfuric acid were from Merck Chemicals (PTY) LTD, Germany, and Minema, South Africa, Batch No. 42980, respectively. The obtained Milli-Q water was from the EMD-Millipore machine (Switzerland). Potassium hydroxide, mono, and dibasic potassium hydrogen phosphate, sodium acetate, and potassium cyanide were provided by Merck Laboratory Supplies (PTY), Midrand, South Africa. The purchased filter disc Grade 292 (125 mm) was from Whatman, Maidstone, England, while Minisart Syringe Filter $(0.22 \mu \mathrm{m})$ was from Bornstein, Germany. All solvents, materials, and reagents used for this research work are of analytical grade.

The HPLC-Shimadzu-UFLC Prominence system with the LC-20AD connecter, LC-2AB pump (20 MPa), SIL-2A autosampler, and SPDA-M20A diode array detector was from Shimadzu Corporation, Kyoto, Japan. The PDA wavelength of the detector was between 190 to $800 \mathrm{~nm}$. The "LC Lab Solution" software performed the system's control, data acquisition, and analysis.

The conducted chromatographic separation was by using the developed method on Luna ${ }^{\oplus}, 5 \mu \mathrm{m}$ C18 (2) $100 \mathrm{~A}$ column $(150 \times 4.6 \mathrm{~mm}$ (Phenomenex, USA). The mobile phase delivery was isocratic and consisted of methanol $(\mathrm{MeOH})$ and 0.02 $\mathrm{M}$ phosphoric acid (PA), $\mathrm{pH}=5.8$ in a ratio of 35:65, v/v $(\mathrm{A} / \mathrm{B})$, respectively. The flow rate was $0.5 \mathrm{~mL} / \mathrm{min}$.

The maintained column temperature was $30{ }^{\circ} \mathrm{C}$, and each analyte injection volume was $20 \mu \mathrm{L}$ for $10 \mathrm{~min}$ run. The recorded Ultraviolet-visible (UV-vis) absorbances were at $270 \mathrm{~nm}$ wavelength [25]. 


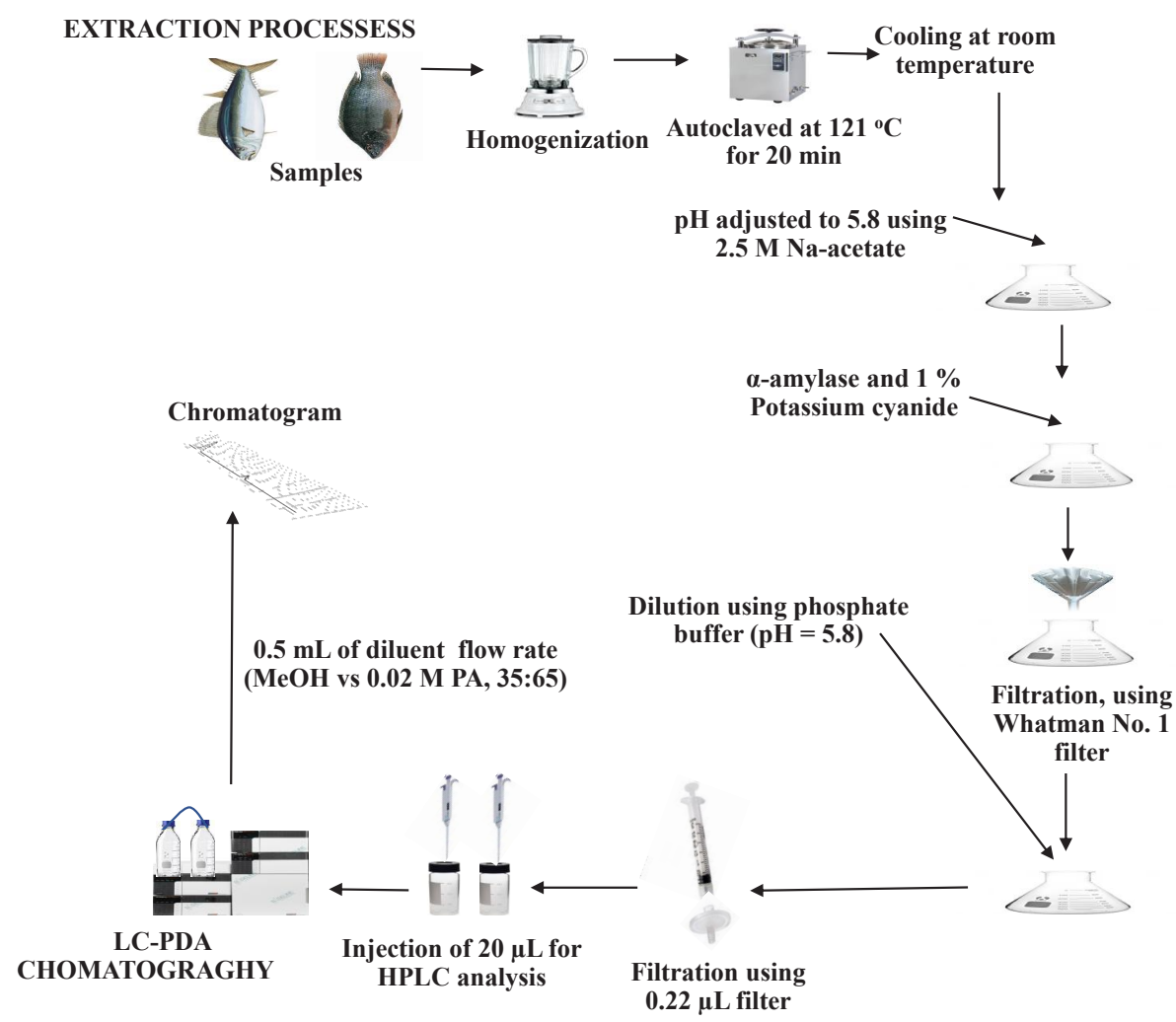

Figure 1. Schematic diagram of samples extraction processes and chromatography.

\section{Results and discussion}

Cobalamin occurs in diverse natural conformation. Therefore, transformation into a single conformation like cyanocobalamin is required. The extraction processes yield this conversion and hence, its identification using a UV-vis detection wavelength of $270 \mathrm{~nm}$. However, the often-used UV detection wavelength by the AOAC official method was 360 $\mathrm{nm}$ [26]. During the optimization of our developed analytical method, both 270 and $360 \mathrm{~nm}$ wavelengths were evaluated. A wavelength of $270 \mathrm{~nm}$ produced a better peaks resolution for the detection of cobalamin. Also, the wavelength yielded a reasonable level of this vitamin. Generally, extraction of B-vitamins can be possible by incubating a sample at $121{ }^{\circ} \mathrm{C}$ for $20 \mathrm{~min}$ in the presence of excess potassium cyanide [6]. From the report of [18], the acid digestion and addition of a-amylase enzyme are significant enough for sample extraction of vitamin B-complexes. For our samples' extractions, both approaches were exercised for maximum yield. Therefore, RP-HPLC using a UV-vis detector is one of the accepted assay methods for separating, identifying, and quantifying vitamins and other organic compounds in pharmaceutical supplements and food formulas [27]. In addition, from the report of [28], the RP-HPLC analysis method coupled to a UV-vis detector was the most reliable, fast, and simple technique for studying water-soluble vitamins in food materials.

The method validation of our developed RP-HPLC complied with the international conference of harmonization (ICH) [29]. The linearity, sensitivity, detection limit (LOD) and quantification limit (LOQ), precision, and accuracy were the characteristics parameters evaluated during our method validation. The analysis of all working solutions was within $24 \mathrm{~h}$ of their preparation.

The linear regression graph analysis was performed in duplicate under a 9-point calibration graph to determine the linearity of the proposed method. The observed response was linear within the above concentration ranges of the standard working solution. The revealed coefficient $\left(R^{2}\right)$ of the linear regression graph and equation were 0.9988 and $y=18912 x-$ 8148.7 ( $\mathrm{x}=$ concentration, $\mathrm{y}=$ peak area), respectively (Figure 2 ).

The LOD and LOQ for the developed method were evaluated based on a signal by comparing 3.3-folds and 10-folds differences of the baseline noise and signal of analytes, respectively. The LOD means a concentration of compound that produces a signal-to-noise ratio of above 3.0. However, the LOQ means a compound concentration equal to 10 times the value of the signal-to-noise ratio. The LOD and LOQ were determined using these formulas; $3.3 \times(\mathrm{S}) / \mathrm{m})$ and $10 \times(\mathrm{S}) / \mathrm{m})$ respectively, as cited by the ICH guidelines [29]. Here $\mathrm{S}$ is standard deviation of $\mathrm{y}$-intercept, and $\mathrm{m}$ is slope of the linear 
regression curve. The determined LOD and LOQ were 0.0004 and $0.0011 \mu \mathrm{g} / \mathrm{mL}$, respectively (Table 1 ). Hence, the LOD and LOQ concentration values determined indicated that the method developed was of high sensitivity.

The assessed method precision (intraday and interday) was by using 2-different concentrations ( 5 and $10 \mu \mathrm{g} / \mathrm{mL})$ of the standard working solution. However, within points in the standard curve, they were not identified. The evaluation of each concentration was in duplicate, and each result presented as a relative standard deviation (RSD) in percentage, which denotes average recovered standard deviation/average recovered concentration $\times 100$. The evaluation of intraday and interday precision were within $24 \mathrm{~h}$ and $48 \mathrm{~h}$, respectively. The recorded interday and intraday values of the precision were in the range of $0.14 \%$ to $0.76 \%$ (Table 2). Similarly, the evaluation for intraday and interaccuracy was in duplicate using the same standard solution concentrations used to determine intraday and interday precision. The presentation of each data for intraday and interaccuracy was as a percentage mean recovery and recorded between $87.44 \pm 0.33 \%$ to $97.08 \pm$ $0.74 \%$, respectively, as depicted in Table 2 . Therefore, the realized low values of the percentage RSD, $\leq 2.5$ as recommended by $\mathrm{AOAC}$, and satisfactorily percentage mean recoveries revealed a high precision and accuracy of the developed isocratic RP-HPLC method for assessing this vitamin.

The determination of accuracy-spike recovery was by assaying each extract of a snoek and tilapia fishes fortified with a known concentration of standard cyanocobalamin called a reference standard in a ratio of 1:1 (v/v). The representative chromatograms of the reference standard (RS), snoek fish (SF) (unspiked extract), snoek fish spiked (SFS) extract, tilapia

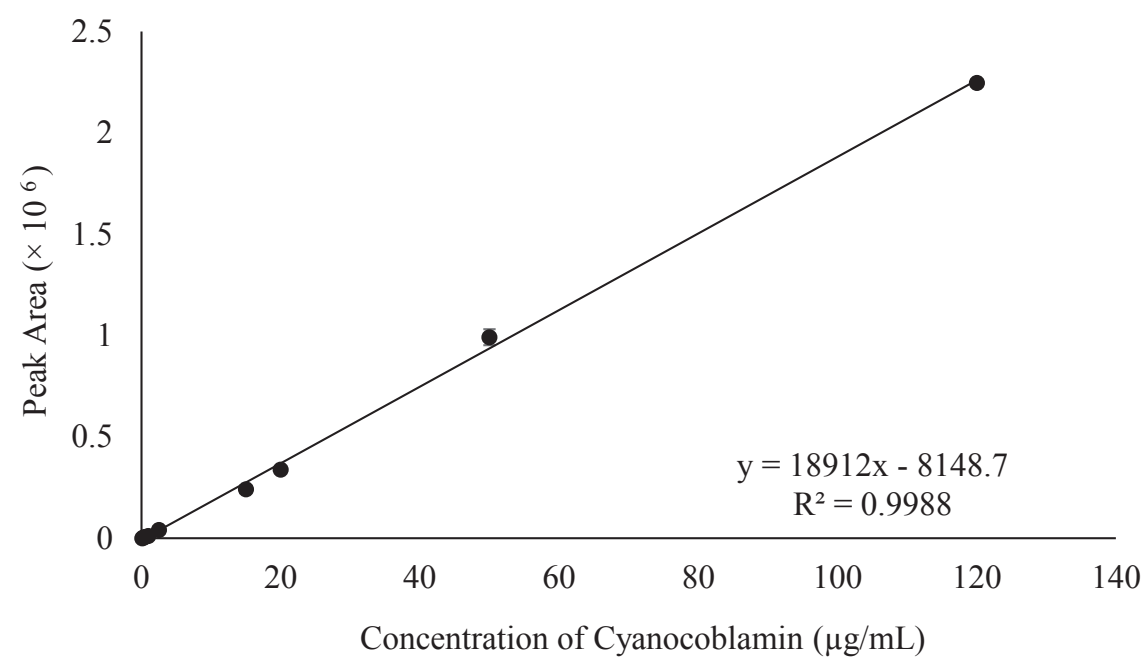

Figure 2. Standard linear regression curve of standard having a 9-points range of concentrations $(0.5$ to $120 \mu \mathrm{g} / \mathrm{mL})$. The y-axis represents the peak area of chromatograms in mAU. However, the $\mathrm{x}$-axis represents the standard (Cyanocobalamin) concentration in $\mu \mathrm{g} / \mathrm{mL}$.

Table 1. Characteristics of the isocratic RP-HPLC method. Values presented were as mean \pm SD in duplicate.

\begin{tabular}{|l|l|}
\hline Characteristic parameters & Cobalamin $\left(\right.$ Vitamin $\left.\mathrm{B}_{12}\right)$ \\
\hline Calibration range of standard, $\mu \mathrm{g} / \mathrm{mL}$ & 0.1 to 120 \\
\hline Correlation coefficient, $\mathrm{R}^{2}$ & 0.9988 \\
\hline Linear regression equation & $\mathrm{y}=18912 \mathrm{x}-8148.7$ \\
\hline $\mathrm{LOD}^{\mathrm{a}}, \mu \mathrm{g} / \mathrm{mL}$ & 0.0004 \\
\hline $\mathrm{LOQ}^{\mathrm{b}}, \mu \mathrm{g} / \mathrm{mL}$ & 0.0011 \\
\hline Wavelength of detection, $\mathrm{nm}$ & 270 \\
\hline
\end{tabular}

${ }^{a}$ LOD, Limit of detection and ${ }^{b}$ LOQ, Limit of quantification 
fish (TF) (unspiked extract), tilapia fish spiked (TFS) extract, and diluting solution (DS) are presented in Figures 3-8, respectively. The determination of the percentage accuracy-spike of each sample extract was by using the relation below. The expression of each result was as a percentage mean recovery (Table 3). Therefore, $\% \mathrm{MR}=((\mathrm{A}-\mathrm{B}) / \mathrm{C})) \times 100$, where $\mathrm{A}, \mathrm{B}$, and $\mathrm{C}$ and $\% \mathrm{MR}$ denotes peak area of the spiked sample extract, the peak area of the unspike sample extract, the peak area of the reference standard, and percentage mean recovery.

Table 2. The precision and accuracy of the developed isocratic RP-HPLC method; values presented were as means \pm SD in duplicate.

\begin{tabular}{|l|l|l|l|l|}
\hline \multirow{2}{*}{ Content, $\mu \mathrm{g} / \mathrm{mL}$} & \multicolumn{2}{|l|}{ Intraday } & \multicolumn{2}{l|}{ Interday } \\
\cline { 2 - 5 } & $\begin{array}{l}\text { Precision } \\
\left(\text { RSD }^{\mathrm{a}}\right), \%\end{array}$ & $\begin{array}{l}\text { Accuracy } \\
(\text { Recovery }), \%\end{array}$ & $\begin{array}{l}\text { Precision } \\
\left(\text { RSD }^{\mathrm{a}}\right), \%\end{array}$ & $\begin{array}{l}\text { Accuracy } \\
(\text { Recovery), \% }\end{array}$ \\
\hline 5 & 0.76 & $97.08 \pm 0.74$ & 0.36 & $96.86 \pm 0.35$ \\
\hline 10 & 0.14 & $90.20 \pm 0.12$ & 0.37 & $87.44 \pm 0.33$ \\
\hline
\end{tabular}

${ }^{a} \mathrm{RDS}$, relative standard deviation

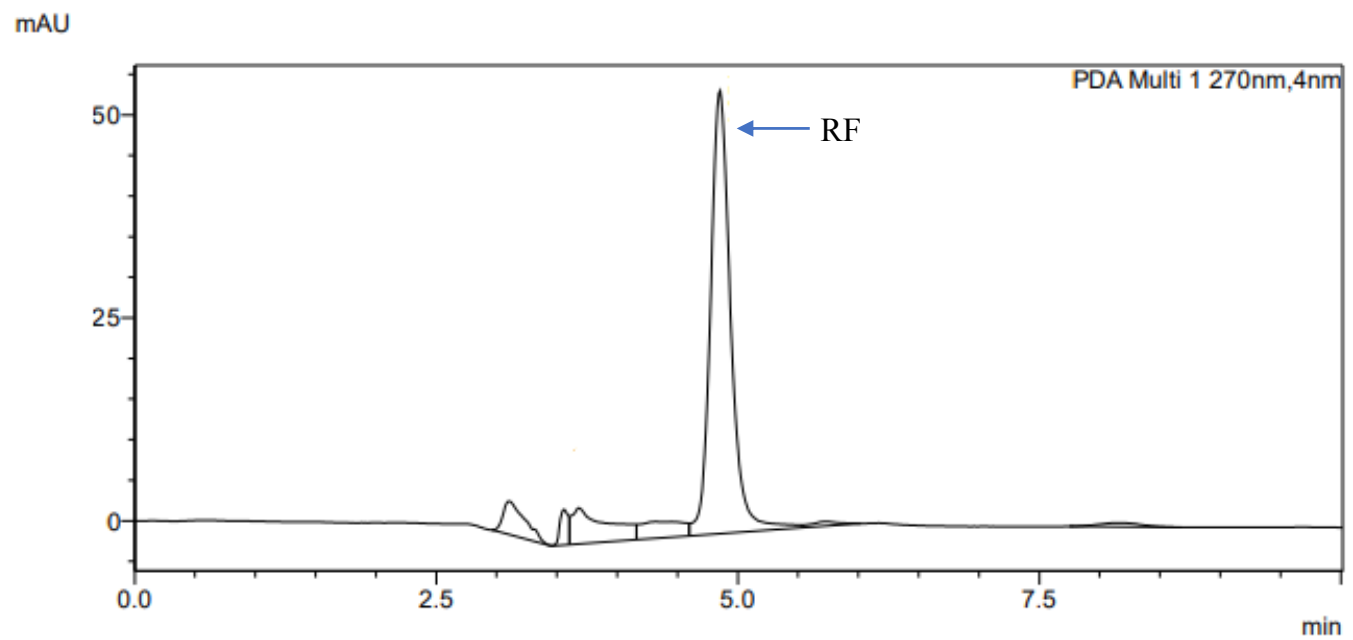

Figure 3. The representative chromatogram for the RS $(30 \mu \mathrm{g} / \mathrm{mL})$.

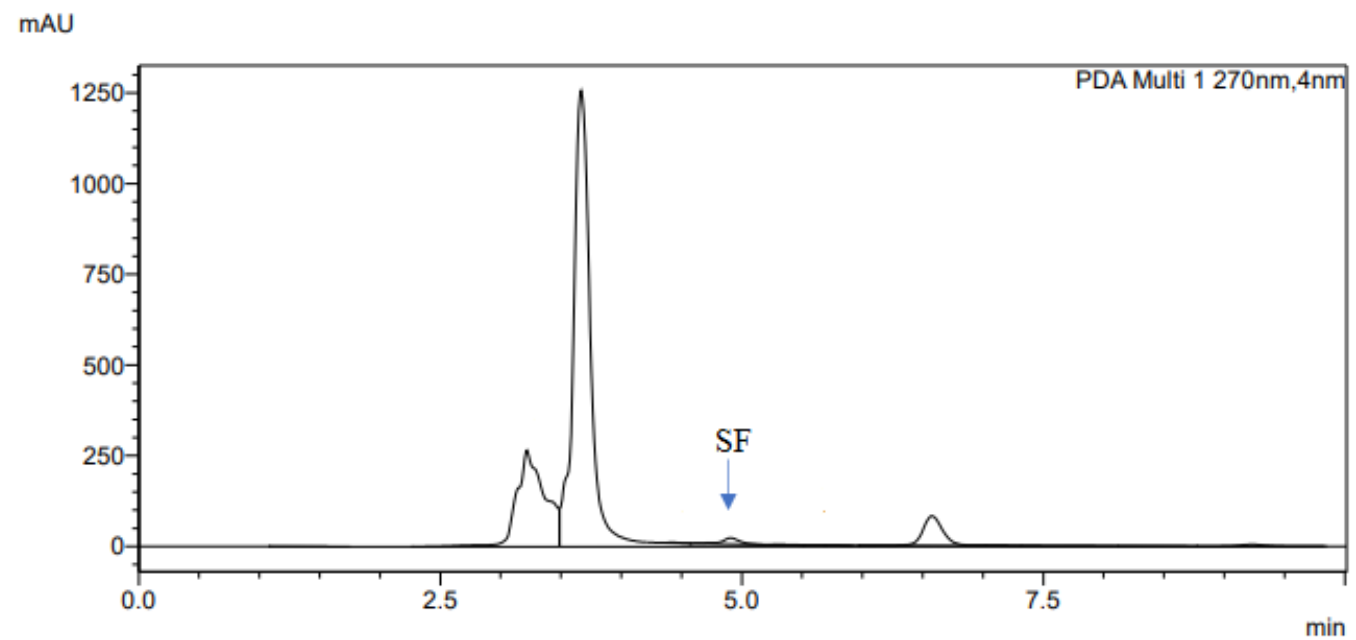

Figure 4. The representative chromatogram for the SF. 
mAU

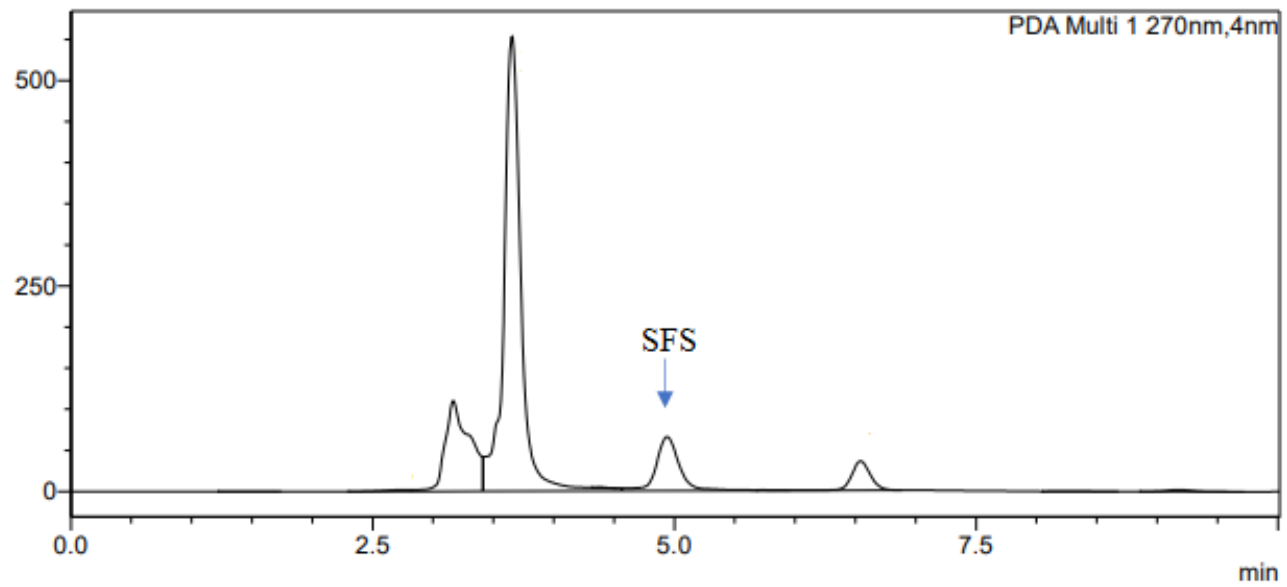

Figure 5. The representative chromatogram for the SFS.

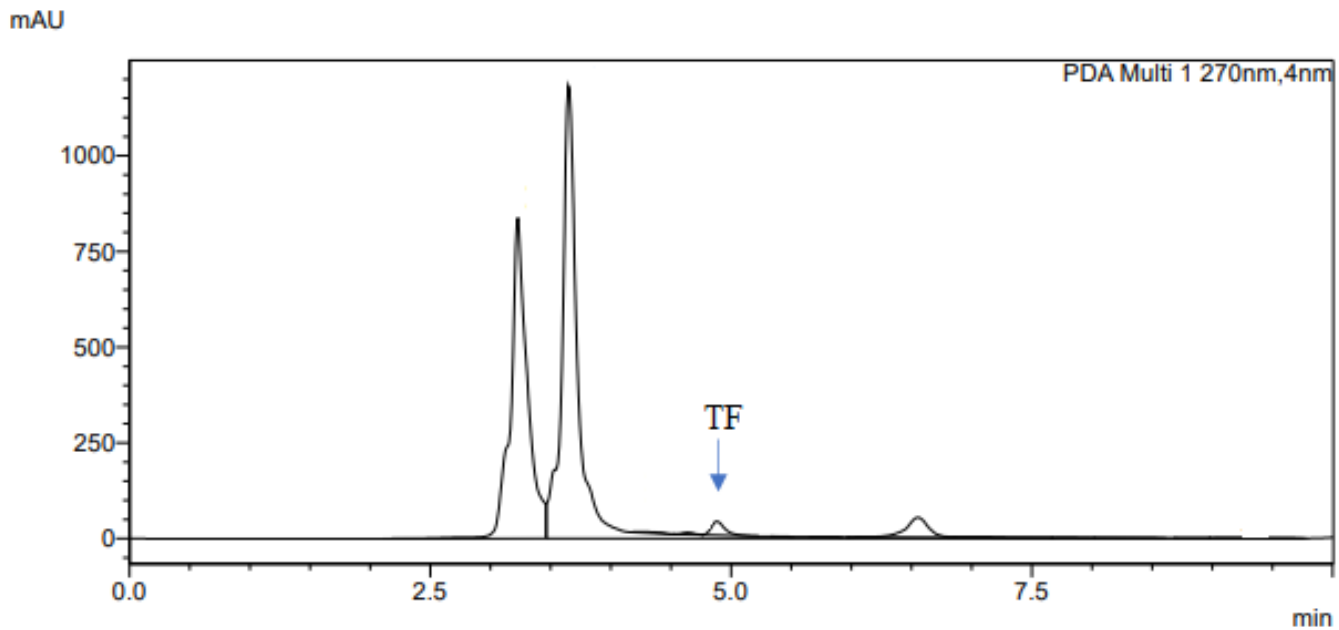

Figure 6. The representative chromatogram for the TF.

mAU

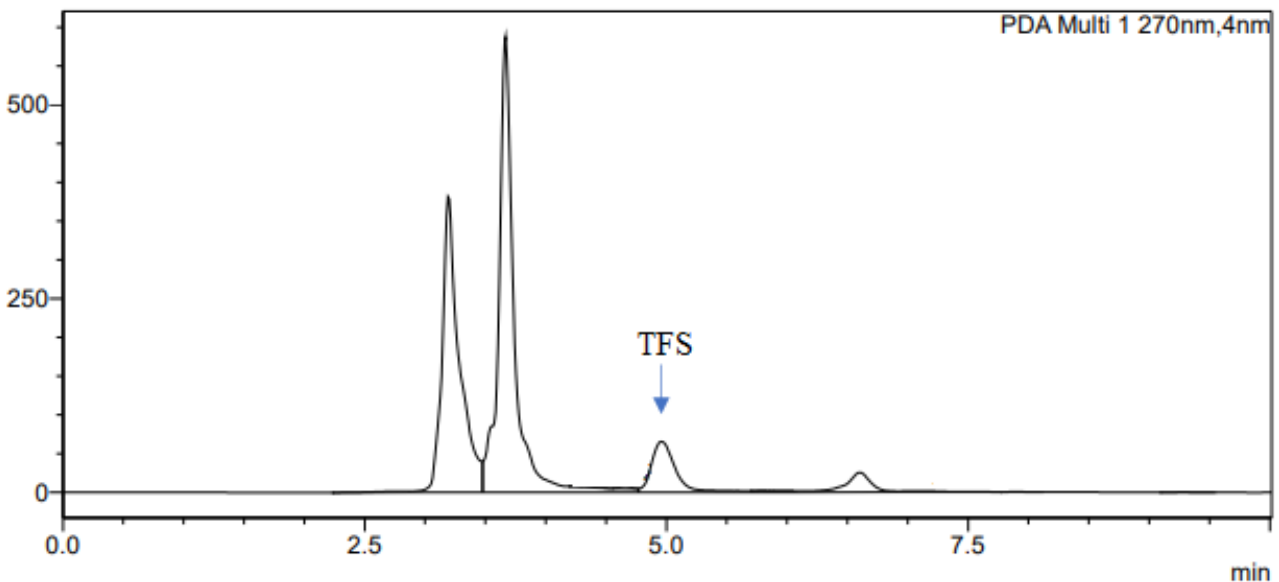

Figure 7. The representative chromatogram for the TFS. 
mAU

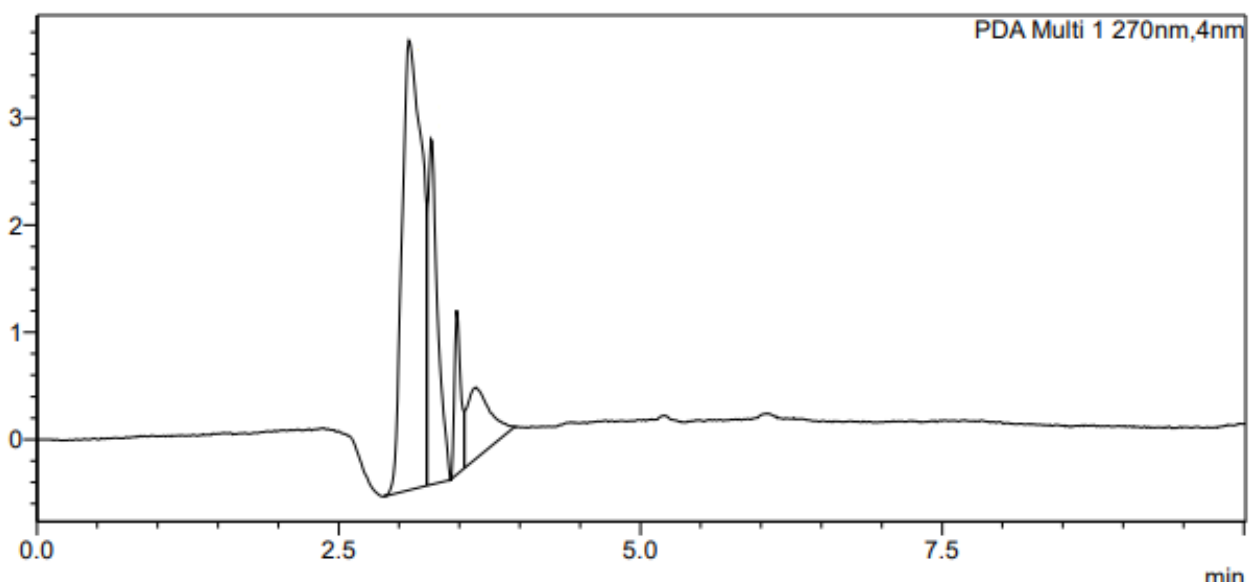

Figure 8. The representative chromatogram for the DS. The above UV-HPLC chromatograms were detected using UV-detector with an isocratic gradient of $35 \%$ methanol and $65 \%$ weak phosphoric acid $(0.02 \mathrm{M})$. The flow rate was $0.5 \mathrm{~mL} / \mathrm{min}$, the injection volume was $20 \mu \mathrm{L}$, and the detection wavelength was $270 \mathrm{~nm}$ wavelength.

Table 3. Accuracy-spiked and measured samples extract concentrations of cobalamin. Values presented were as means \pm SD in duplicate.

\begin{tabular}{|l|l|l|}
\hline Name of samples & Accuracy-spike level, \% & Concentration of Cobalamin, $\mu \mathrm{g} / \mathrm{mL}$ \\
\hline Aquaponics tilapia fish & $102.59 \pm 0.09$ & $14.97 \pm 0.04$ \\
\hline Marine snoek fish & $110.84 \pm 1.18$ & $08.95 \pm 0.35$ \\
\hline
\end{tabular}

Table 4. Analytes chromatograms' retention times. Values presented were as mean \pm SD in duplicate.

\begin{tabular}{|l|l|}
\hline Analytes & Retention time, min \\
\hline RS & $4.98 \pm 0.19$ \\
\hline SF & $4.92 \pm 0.01$ \\
\hline SFS & $4.95 \pm 0.01$ \\
\hline TF & $4.89 \pm 0.03$ \\
\hline TFS & $4.95 \pm 0.02$ \\
\hline
\end{tabular}

RS; reference standard, SF; snoek fish extract, SFS; snoek fish spiked, TF; tilapia fish extract, TFS; tilapia fish spiked.

Each extract quantification of cobalamin (Table 3) was expressed in $\mu \mathrm{g} / \mathrm{mL}$ and calculated using a linear regression equation, $y=18912 x-8148.7$ (where, $x=$ concentration, $y=$ peak area). The amount of cobalamin obtained from this study was compatible with meat products' reported work [6]. It was higher than the amount revealed using okra extracts from 4 different geographical locations as reported in [19]. The recommended nutrient intake of cobalamin by US-NAS (United States National Academy of Science) ranges between 0.4 and $2.8 \mu \mathrm{g} /$ day for all age groups, including pregnant and lactation mothers. However, older individuals may require a higher amount per day [30]. From levels of cobalamin obtained from our study, the sample extracts, therefore, denoted good dietary sources of this vitamin.

The retention times of various chromatograms presented in Figures 3-8 and the consistency of our developed RPHPLC method with previously cited ones were given in Tables 4 and 5, respectively. Therefore, our method was revealed 
Table 5. Various RP-HPLC methods consistency-comparison for the determination of B-vitamins.

\begin{tabular}{|c|c|c|}
\hline $\mathrm{S} / \mathrm{N}$ & Methods properties & Values reported \\
\hline \multirow{10}{*}{1.} & Regression $\left(\mathrm{R}^{2}\right)$ & 0.9988 \\
\hline & $\mathrm{LOD}, \mu \mathrm{g} / \mathrm{mL}$ & 0.0004 \\
\hline & $\mathrm{LOQ}, \mu \mathrm{g} / \mathrm{mL}$ & 0.0011 \\
\hline & Precision (RSD), \% & $0.76-0.36$ \\
\hline & Percentage recovery, \% & $87.44-90.20$ \\
\hline & Retention time, min & $4.87-4.98$ \\
\hline & Detection wavelength, nm & 270 \\
\hline & Detected level, $\mu \mathrm{g} / \mathrm{mL}$ & $8.95-14.97$ \\
\hline & Sample extracts & Fishes (Tilapia and Snoek) \\
\hline & Reference & {$\left[{ }^{\star}\right]$} \\
\hline \multirow{10}{*}{2.} & Regression $\left(\mathrm{R}^{2}\right)$ & 0.9950 \\
\hline & $\mathrm{LOD}, \mu \mathrm{g} / \mathrm{mL}$ & 0.2000 \\
\hline & $\mathrm{LOQ}, \mu \mathrm{g} / \mathrm{mL}$ & 0.3800 \\
\hline & Precision (RSD), \% & $\mathrm{nr}$ \\
\hline & Percentage recovery, \% & $\mathrm{nr}$ \\
\hline & Retention time, min & 16.00 \\
\hline & Detection wavelength, nm & 210 \\
\hline & Detected level, $\mu \mathrm{g} / \mathrm{mL}$ & nr (lower than LOD) \\
\hline & Sample extracts & Polyvitaminated premixes \\
\hline & Reference & {$[15]$} \\
\hline \multirow{10}{*}{3.} & Regression $\left(\mathrm{R}^{2}\right)$ & 0.9990 \\
\hline & $\mathrm{LOD}, \mu \mathrm{g} / \mathrm{mL}$ & $\mathrm{nr}$ \\
\hline & $\mathrm{LOQ}, \mu \mathrm{g} / \mathrm{mL}$ & 0.007 \\
\hline & Precision (RSD), \% & $1.50-7.26$ \\
\hline & Percentage recovery, \% & $79.61-108.80$ \\
\hline & Retention time, min & 7.17 \\
\hline & Wavelength, nm & 361 \\
\hline & Detected level, $\mu \mathrm{g} / \mathrm{mL}$ & $3.85-8.78$ \\
\hline & Sample extract & Meat products \\
\hline & Reference & {$[6]$} \\
\hline \multirow{10}{*}{4.} & Regression $\left(\mathrm{R}^{2}\right)$ & 0.9910 \\
\hline & $\mathrm{LOD}, \mu \mathrm{g} / \mathrm{mL}$ & 0.0625 \\
\hline & LOQ, $\mu \mathrm{g} / \mathrm{mL}$ & 0.1250 \\
\hline & Precision (RSD), \% & $0.40-4.10$ \\
\hline & Percentage recovery, \% & $90.40-108.50$ \\
\hline & Retention time, min & 6.53 \\
\hline & Wavelength, nm & 350 \\
\hline & Detected level, $\mu \mathrm{g} / \mathrm{mL}$ & 45.86 \\
\hline & Sample extracts & Multivitamin tablets \\
\hline & Reference & {$[20]$} \\
\hline
\end{tabular}


Table 5. (Continued).

\begin{tabular}{|l|l|l|}
\hline \multirow{5}{*}{5.} & Regression $\left(\mathrm{R}^{2}\right)$ & 0.9990 \\
\cline { 2 - 3 } & $\mathrm{LOD}, \mu \mathrm{g} / \mathrm{mL}$ & 0.1600 \\
\cline { 2 - 3 } & $\mathrm{LOQ}, \mu \mathrm{g} / \mathrm{mL}$ & 0.5200 \\
\cline { 2 - 3 } & Precision $(\mathrm{RSD}), \%$ & $1.41-4.64$ \\
\cline { 2 - 3 } & Percentage recovery, \% & $96.00-10.10$ \\
\cline { 2 - 3 } & Retention time, min & 5.70 \\
\cline { 2 - 3 } & Detecttion wavelength & 228 \\
\cline { 2 - 3 } & Detected level, $\mu \mathrm{g} / \mathrm{mL}$ & $1.80-2.69$ \\
\cline { 2 - 3 } & Sample extract & Dietary supplements and ingredients \\
\cline { 2 - 3 } & Reference & {$[21]$} \\
\hline
\end{tabular}

$\left[{ }^{*}\right]=$ Our developed RP-HPLC method.

to be even more precise (\% RSD), sensitive (LOD and LOQ), and rapid (retention time) when compared with previous findings.

\section{Conclusion}

The isocratic liquid chromatography method we developed for this research study was simple, rapid, linear, sensitive, precise, and accurate. Moreover, from the results obtained, our extraction method indicated that the extraction and separation of this vitamin were satisfactory.

Therefore, the developed method can be vibrant to the food and pharmaceutical industries for routine product quality control and nutritional labeling. Also, the method could be of importance to clinical laboratories for diagnostic analysis. Moreover, data obtained could be applicable as food-based dietary guidelines, nutrition education, and a food composition database.

\section{References}

1. Anyakora C, Afolami I, Ehianeta T, Onwumere F. HPLC analysis of nicotinamide, pyridoxine, riboflavin, and thiamin in some selected food products in Nigeria. African Journal of Pharmacy and Pharmacology 2008; 2: 029-036.

2. Pavlos FC, Victoria FS, Ioannis NP. Development of a validated liquid chromatography method for the simultaneous determination of eight fat-soluble vitamins in biological fluids after solid-phase extraction. Journal of Chromatography A 2004; 805: 289-296. doi: 10.1016/j.jchromb.2004.03.009

3. Ortigues-Marty I, Micol D, Prache S, Dozias D, Girard, CL. Nutritional value of meat: the influence of nutrition and physical activity on vitamin $B_{12}$ concentrations in ruminant tissues. Reproduction, Nutrition, Development 2005; 45: 453-467. doi: 10.1051/rnd:2005038

4. Elfalleh W, Nasri N, Marzougui, N. Physicochemical properties and DPPH-ABTS scavenging activity of some local pomegranate (Punica granatum) ecotypes. International Journal of Food Sciences and Nutrition 2009; 60 (2): 197-210. doi: 10.1080/09637480903067037

5. Laurence P. Vitamin $B_{12}$ - A review of analytical methods for use in food. Government Chemist Program, Report in 2005; National Measurement System, UK, 2015Report No. LGC/R/2014/378, 2015.

6. Guggisberg D, Risse MC, Hadorn R. Determination of Vitamin $B_{12}$ in meat products by RP-HPLC after enrichment and purification on an immunoaffinity column. Meat Science 2012; 90: 279-283. doi: 10.1016/j.meatsci.2011.07.009

7. van Breemen R, Betz JM, Evans L, Hall A, Jennens M. et al. AOAC SMPR 2016.017. Journal of AOAC International 2017; 100 (1): $294-296$. doi: 10.5740/jaoacint.smpr2016.014

8. Chen P, Wolf WR, Castanheira I, Sanches-Silva A. A LC/UV/Vis method for determination of cyanocobalamin $\left(\mathrm{VB}_{12}\right)$ in multivitamin dietary supplements with on-line sample clean-up. Analytical Methods 2010; 2 (8): 1171-1175. doi: 10.1039/c0ay00177e

9. Stabler SP. Vitamin $B_{12}$. In Bowman BA, and Russell RM. Present Knowledge in Nutrition. DC: ILSI Press, Washington, USA, 2006, pp. 302-313.

10. Selhub J. Folate, vitamin $B_{12}$ and vitamin $B_{6}$ and one-carbon metabolism. The Journal of Nutrition, Health and Aging $2002 ; 6$ (1): $39-42$. 
11. Pawlak R, Parrott SJ, Raj S, Cullum-Dugan D, Lucus D. How prevalent is vitamin $B_{12}$ deficiency among vegetarians? Nutrition Reviews 2013; 71 (2): 110-117. doi: 10.1111/nure.12001

12. US-DHHS (United States Department of Health and Human Service. Dietary guidelines for Americans 2010; $8^{\text {th }}$ ed. Washington, DC, 2010, pp. 1-164.

13. Frenkel EP, Prough R, Kitchens RL. Measurement of tissue vitamin $B_{12}$ by radioisotopic competitive inhibition assay and quantitation of tissue cobalamin fractions. Methods in Enzymology 1980; 7: 31-40. doi: 0.1016/S0076-6879(80)67008-6

14. Indyk HE, Persson BS, Caselunghe MCB, Moberg A, Filouzi EL et al. Determination of Vitamin $B_{12}$ in milk products and selected foods by optical biosensor protein-binding assay: method comparison. Journal of AOAC International 2002; 85: 72-82.

15. Heudi O, Kilinc T, Fontannaz P, Marley E, Determination of vitamin $B_{12}$ in food products and in premixes by reversed-phase highperformance liquid chromatography and immunoaffinity extraction. Journal of Chromatography A 2006; 1101: 63-68. doi: 10.1016/j. chroma.2005.09.059

16. AOAC. Official Method 986.23. Cobalamin in milk-based infant formula. AOAC International 2006.

17. Kumar SS, Chouhan RS, Thakur MS. Trends in analysis of vitamin $B_{12}$. Analytical Biochemistry 2010; 398 (2): 139-149. doi: 10.1016/j. ab.2009.06.041

18. Albal'a-Hurtado S, Veciana-Nogu'es MT, Izquierdo-Pulido M, Marin'e-Font A. Determination of water-soluble vitamins in infant milk by high-performance liquid chromatography. Journal of Chromatography A 1997; 78 (1-2): 247-253.

19. Sami R, Li Y, Qi B, Wang S, Zhang Q et al. HPLC Analysis of Water-Soluble Vitamins $\left(\mathrm{B}_{12}, \mathrm{~B}_{3}, \mathrm{~B}_{6}, \mathrm{~B}_{12}\right.$, and C) and Fat-Soluble Vitamins (E, $\mathrm{K}, \mathrm{D}, \mathrm{A}$, and $\beta$-Carotene) of Okra (Abelmoschus esculentus). Journal of Chemistry 2014; 2014: 1-6. doi: 10.1155/2014/831357

20. Amidzic R, Brboric J, Cudina O, Vladimirov S. RP-HPLC determination of vitamins $B_{1}, B_{3}$, $B_{6}$, folic acid and $B_{12}$ in multivitamin tablets. Journal of the Serbian Chemical Society 2005; 70 (10): 1229-1235. doi: 10.2298/JSC0510229A

21. Qiu X, Zhanga H, Yina Y, Brandesb H, Marsalab T et al. Determination of active vitamin $B_{12}$ (cobalamin) in dietary supplement and ingredients by reverse-phase liquid chromatography: Single-laboratory validation. Food Chemistry 2019; 298: 1-6. doi: 10.1016/j. foodchem. 2019.125010

22. Schwertner HA, Valtier S, Bebarta VS. Liquid chromatographic mass spectrometric (LC/MS/MS) determination of plasma hydroxocobalamin and cyanocobalamin concentrations after hydroxocobalamin antidote treatment for cyanide poisoning. Journal of Chromatography B 2012; 905: 10-16. doi: 10.1016/j.jchromb.2012.07.012

23. AOAC International 1990; Official Methods of Analysis. 5th ed. Arlington, Va, USA.

24. Monajjemzadeh F, Ebrahimi F, Zakeri-Milani P, Valizadeh H. Effects of formulation variables and storage conditions on light protected vitamin $B_{12}$ mixed parenteral formulations. Advanced Pharmaceutical Bulletin 2014; 4 (4): 329-338. doi: 10.5681/apb.2014.048

25. Marzougui N, Guasmi F, Mkaddem M. Assessment of Tunisian Trigonella foenum graecum diversity using seed vitamin $B_{6}, B_{1}, B_{9}$ and $C$ contents. Journal of Food, Agriculture and Environment 2009; 7 (1); 56-61.

26. Gimenez EC, Martin F. Vitamin $B_{12}$ (cyanocobalamin) in Infant Formula Adult/Pediatric Nutritional Formula by Liquid Chromatography with Ultraviolet Detection: Collaborative Study. Final Action 2014.02, Journal of AOAC International 2018.

27. US-FDA (United States Department of Food and Drugs Administration), Analytical Procedures and Methods Validation for Drugs and Biologics 2015. New Hampshire Ave., Hillandale Bldg., Silver Spring, MD 20993.

28. Heudi O, Kilin T, Fontannaz P. Separation of water-soluble vitamins by reversed-phase high-performance liquid chromatography with ultra-violet detection: application to poly-vitaminated premixes. Journal of Chromatography A 2005; 1070 (1-2): 49-56.

29. ICH Q2(R1) 2005; Expert Working Group ICH Harmonized tripartite guidelines validation of analytical procedures. Text and methodology, step 4, pp. 1-18.

30. US-NAS (United States National Academy of Sciences). Dietary reference intakes for thiamin, riboflavin, niacin, vitamin $\mathrm{B}_{6}$, folate, and vitamin $B_{12}$, pantothenic aid, biotin, and choline 1998. National Academy Press, Washington DC, USA. doi: 10.17226/6015 